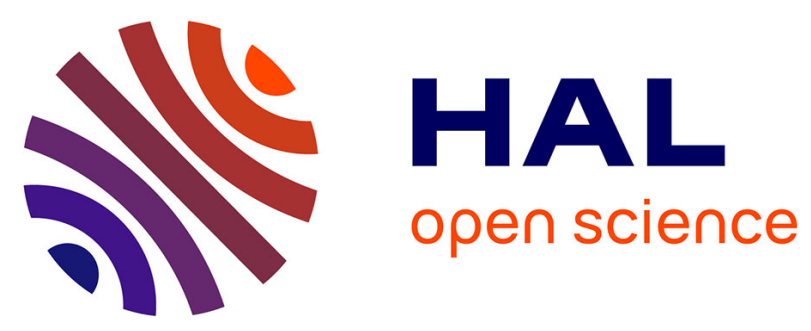

\title{
Influence of filler wire composition on weld microstructures of a 444 ferritic stainless steel grade
}

Vincent Villaret, Frédéric Deschaux-Beaume, Cyril Bordreuil, Sébastien Rouquette, Corinne Chovet

\section{- To cite this version:}

Vincent Villaret, Frédéric Deschaux-Beaume, Cyril Bordreuil, Sébastien Rouquette, Corinne Chovet. Influence of filler wire composition on weld microstructures of a 444 ferritic stainless steel grade. Journal of Materials Processing Technology, 2013, 213, pp.474-483. 10.1016/j.jmatprotec.2013.03.026 . hal-00825145

\section{HAL Id: hal-00825145 \\ https://hal.science/hal-00825145}

Submitted on 23 May 2013

HAL is a multi-disciplinary open access archive for the deposit and dissemination of scientific research documents, whether they are published or not. The documents may come from teaching and research institutions in France or abroad, or from public or private research centers.
L'archive ouverte pluridisciplinaire HAL, est destinée au dépôt et à la diffusion de documents scientifiques de niveau recherche, publiés ou non, émanant des établissements d'enseignement et de recherche français ou étrangers, des laboratoires publics ou privés. 


\title{
Influence of filler wire composition on weld microstructures of a 444 ferritic stainless
} steel grade

V. Villaret ${ }^{1,2}$, F. Deschaux-Beaume ${ }^{1}$, C. Bordreuil ${ }^{1}$, S. Rouquette ${ }^{1}$, C. Chovet $^{2}$

${ }^{1}$ Université Montpellier II, Mechanical and Civil Engineering Laboratory, 30907 Nîmes, France.

${ }^{2}$ Air Liquide, Saint Ouen l'Aumône, France.

\begin{abstract}
Seven compositions of metal cored filler wires for Gas Metal Arc Welding (GMAW), containing the same weight percent of chromium (Cr) and molybdenum (Mo) as 444 steel, but with different titanium ( $\mathrm{Ti}$ ) and niobium $(\mathrm{Nb})$ contents were investigated. Experimental results pointed out that the filler wire Ti content required to be twice time more than the amount expected in the deposited metal. This was due to the low Ti transfer ratio during arc welding. Moreover, Ti increased the wetting angle and promoted penetration. It was supposed that Ti affected the weld pool surface tension what led to inward Marangoni convection. Columnar to equiaxed grain transiton (CET) was also promoted thanks to the precipitation in the weld pool of Ti rich refractory compounds which act as heterogeneous nucleation sites for equiaxed grains. A minimum $0.3 \% \mathrm{Ti}$ was required in the filler wire to form a completely equiaxed grain structure in the fusion zone. Niobium in the filler wire did not seem to have any effect on penetration, wetting and grain structure of the fusion zone.
\end{abstract}

Keywords: ferritic stainless steel, GMAW, filler wire, columnar to equiaxed transition, grain structure, fusion zone. 


\section{Introduction}

Evolution of European anti-pollution standards have imposed on automotive manufacturers to reduce drastically their new vehicles pollutants emissions. The main recent developments have concerned both vehicle weigh reduction and the improvement of engine efficiency of new cars what helped saving fuel consumption. The last development resulted in an increase of the exhaust gas temperature.

During the last past years, numerous investigations were conducted to improve design and heat resistance of gas manifolds. Hot exhaust gas are collected through the manifold then this part is subjected to high temperatures. Exhaust gas temperature reaches up to $1000^{\circ} \mathrm{C}$ for new vehicles with high performance engines. Santacreu et al. $(2004,2006)$ presented a new design approach to replace traditional manifolds made of cast iron to stainless steel tubes which are formed and welded.

Ferritic stainless steels (FSS) were selected for such applications thanks to their good resistance to both cyclic oxidation and thermal fatigue due to their low thermal expansion coefficient compared to austenitic stainless steels. FSS are also cheaper because they do not contain nickel. However, FSS have generally low creep strength and resistance to isothermal oxidation at high temperature. Furthermore, Pickering (1978) indicated that FSS were also sensitive to intergranular corrosion, especially during welding process. This is due to the precipitation of chromium rich carbides/intermetallics at grain boundaries which create a zone of Cr depletion more sensitive to corrosion in the matrix. Demo (1974) tried to reduce this sensitization phenomenon by decreasing the carbon content. Unfortunately it required expensive purification processes. Gordon and Van Bennekom (1996) have shown that the sensitization of FSS could be reduced with addition of some stabilizing elements like niobium or titanium. So, titanium or niobium carbides are favoured instead of chromium carbides. 
Moreover Fujita et al. (2003) have demonstrated that the addition of a few content of stabilizing elements like $\mathrm{Nb}$ improved also high temperature strength and creep resistance. Since 1980's, FSS grades were introduced for exhaust systems of upper class vehicles. You et al. (2007) compared heat resistance of various FSS grades used for automotive exhaust systems. Special 409 grade with $12 \%$ chromium, niobium, low carbon (C) and nitrogen (N) contents was the first one to be employed for exhaust systems. However its oxidation resistance was low at high temperature what prevented any use with new high performance engines. Grades containing 17-19\% chromium (430 type) exhibited better resistance to high temperature oxidation. Unfortunately martensite was created after heat treatment and rapid cooling what had an embrittling effect. Finally, stabilized 430 FSS grades containing Ti or grades 444 containing $18 \% \mathrm{Cr}$ and $2 \%$ Mo have been recently developed instead. These last ones are also called "superferritic" due to the high stability of ferrite at all temperature. Miyasaki et al. (2003) and later Potgieter et al. (2007) observed that addition of molybdenum improved drastically resistance to cyclic oxidation as well as high temperature strength of the steel.

Different parts of the exhaust systems made of ferritic stainless steel tubes are welded together along the manufacturing process. Unfortunately, microstructure and then the base material properties are modified during the welding process. The so called "heat affected zone" (HAZ) in the base material is created due to the local heating and rapid cooling induced during welding. HAZ is subjected to microstructural changes. 409 or 430 grades with medium $\mathrm{Cr}$ percentage presented some austenite at high temperature as well, especially with high C and N contents. Due to this transformation, Xinzhong et al. (2008) observed some martensite in the HAZ of 430 grade. As explained by Greeff and Du Toit (2006) then Amuda and Mridha (2011), a sensitization mechanism could have also occurred in the HAZ of FSS even with stabilizing elements. Titanium or niobium carbides could be partially dissolved at high 
temperature that led to the precipitation of chromium carbides during rapid cooling. They were thermodynamically less stable but kinetically more favourable. Silva and Farias (2008) observed the apparition of Laves or sigma phases in 444 grade that could have also decreased the corrosion resistance of ferritic stainless steels. Welding of FSS have also generated a grain growth in the HAZ due to the absence of allotropic transformation which had a detrimental effect on the fatigue strength.

The microstructure of the fusion zone is generally very different from the base metal. This partly results from composition differences due to the dilution of the base metal with the filler metal generally used in arc welding and also due to the molten metal interaction with surrounding atmosphere. According to Bayraktar et al. (2006) for instance, contents of C and $\mathrm{N}$ gamma stabilizers were generally higher in the fusion zone which promoted the formation of gamma phase at high temperature then martensite after rapid cooling. Grains size and morphology could have also been very different in the fusion zone. Large columnar grains were often observed in the fusion zone due to the thermal gradient. According to the results obtained by Lakshminarayanan et al. (2009), the large grain size in the fusion zone conferred poor properties in terms of ductility, toughness and fatigue strength. Taban et al. (2009) obtained thinner grains while increasing the cooling rate with the use of a high speed welding process. But Flemings (1974) stated that a constitutional undercooling in the liquid near the solidification front permitted the development of equiaxed grain structure instead of a columnar structure in the fusion zone. Bayraktar et al. (2006) explained that this phenomena could be achieved when the thermal gradient was low and/or the solidification rate was high. The constitutional undercooling promoted the columnar to equiaxed grains transition (CET). Nucleation and growth of equiaxed grains in the undercooled liquid stopped the columnar grain growth. CET could have been also promoted with addition of "inoculants" elements that created nucleation sites for equiaxed grains in the undercooling zone. Ostrowski 
and Langer (1979) investigated the effect of titanium inoculant in cast FSS. This element formed refractory compounds in the molten steel, that promoted the heterogeneous nucleation of the ferritic grains. Villafuerte et al. (1995) then Amuda and Mridha (2012) have demonstrated that titanium had a similar effect in the fusion zone during welding of FSS. However, Mallaiah et al. (2012) observed that formed refractory compounds in the fusion zone could have a detrimental effect on the mechanical properties, especially if they had a large size.

GMAW is one of the most used welding processes in automotive industry, especially for welding exhaust systems made of stainless steel tubes. This process requires the use of a filler metal in the form of metallic wire. In order to improve the life time of exhaust systems used with new high performance engines, Aperam Europe recently developed a new grade of 444 ferritic stainless steel, called K44X. Unfortunately, there is no currently GMAW filler wire available with composition similar to $\mathrm{K} 44 \mathrm{X}$ that allows homogeneous welding. Faivre et al. (2011) recently demonstrated that heterogeneous welding of K44X with austenitic filler metal was not suitable for such application. Cyclic oxidation and thermal fatigue strength of such assemblies were too low due to the difference of thermal expansion coefficient between base metal and fusion zone. Therefore, development of filler wires compatible with the newly developed K44X FSS grade is imperative to get homogeneous welding without sacrificing microstructural stability and weld properties.

The present work investigated filler wires of different compositions particularly of titanium and niobium element for the welding of a K44X grade of ferritic stainless steel with a view to evaluating the compatibility of these different filler wires with the K44X alloy for the production of welds with homogenous composition and microstructure across the weld region and the base metal. 


\section{Experimental Details}

\subsection{Base Metal}

Aperam Europe developed a new ferritic stainless steel K44X base material especially for exhaust systems where important mechanical loading and corrosive atmosphere are generated $\mathrm{du}$ to the temperature working conditions. K44X is similar to AISI 444 designation according to American Standard (ASTM). Its chemical composition is shown in table 1. K44X was made with $19 \%$ chromium, low carbon content $(0.015 \%)$ and $1.9 \%$ of molybdenum. This last element was added in order to give K44X a better oxidation resistance at high temperature than more common 430 steel grade or than austenitic stainless steels like 309 grade (Santacreu et al., 2011).

\section{Table 1}

Composition of K44X grade.

\begin{tabular}{llllllll}
\hline Element & $\mathrm{C}$ & $\mathrm{Mn}$ & $\mathrm{Si}$ & $\mathrm{Cr}$ & $\mathrm{Mo}$ & $\mathrm{Nb}$ & $\mathrm{N}$ \\
\hline Weight \% & 0.015 & 0.3 & 0.6 & 19.0 & 1.9 & 0.6 & 0.015 \\
\hline
\end{tabular}

High weight percent of niobium was also added to K44X steel in order to reduce sensitization issues after welding. This element is known to form refractory precipitates that improves creep strength and limits the grain growth in the HAZ of welds. K44X steel has a very good resistance to thermal fatigue due to its low thermal expansion coefficient $\left(11.910^{-6} \mathrm{~K}^{-1}\right.$ from 20 to $\left.800{ }^{\circ} \mathrm{C}\right)$.

\subsection{Development of Filler Wires}


Chromium and molybdenum contents of the filler metals were chosen equal to the base metal in the aim to ensure a good oxidation resistance of the fusion zones. Niobium was also added in order to improve high temperature strength as well as titanium to promote equiaxed grain formation in the fusion zone. Weight percents of these two elements had to be precisely controlled to avoid detrimental effects on toughness and ductility due to growth or coalescence of precipitates in the fusion zone.

Several compositions of filler wires were first developed in order to investigate the effect of some additional elements on fusion zone composition and grain morphology. Metal cored filler wires were used in order to allow composition changes in the filler metals without using expensive manufacturing process. These products were well suited to this current study because the additional elements could have been easily introduced as powder mixture in the wire core. The external foil of the filler wire was made of AISI 409 stainless steel, containing $12 \% \mathrm{Cr}$ and $0.2 \% \mathrm{Ti}$ (Table 2).

\section{Table 2}

Composition of the foil and global compositions of metal cored filler wires used for preliminary welding (wt $\%)$.

\begin{tabular}{lllllll}
\hline Element & $\mathrm{C}$ & $\mathrm{N}$ & $\mathrm{Cr}$ & $\mathrm{Mo}$ & $\mathrm{Ti}$ & $\mathrm{Nb}$ \\
\hline Foil & 0.017 & & 11.5 & 0.023 & 0.18 & 0.009 \\
\hline Filler wire 0 & 0.015 & $<0.015$ & 18.6 & 1.96 & 0.14 & 0.01 \\
\hline Filler wire 1 & 0.016 & $<0.015$ & 18.5 & 1.93 & 0.74 & 0.01 \\
\hline
\end{tabular}

$\mathrm{Cr}, \mathrm{Mo}, \mathrm{Nb}$ and $\mathrm{Ti}$ additional contents were adjusted in the powder mixture of the core in the aim to obtain the desired composition in the filler metal. 
The "Chemetron" manufacturing technology was used for making metal cored filler wire (US Patent $\left.\mathrm{n}^{\circ} 4282420,1981\right)$. The external foil was first rolled to form a $\mathrm{U}$ shape then the powder mixture was added. The foil was closed by overlapping it while making a $\mathrm{O}$ shape. Finally, a $1.2 \mathrm{~mm}$ diameter filler wire was obtained after several forming passes of the metal cored wire in drawing dies.

Preliminary tests were conducted in order to determine the relation between the global composition of the filler wire (foil + flux) and the composition of deposited metal before developing any filler wires with various compositions. Indeed, the composition of deposited metal was different from the filler wire because some elements were lost due to vaporization or reaction during the phenomenon of chemical transfer in the arc. For instance, titanium has a great affinity with oxygen so it was expected that its content in the deposited metal was lower than in the filler wire. Titanium content in the fusion zone also had a great influence on the microstructural characteristics that is why it was important to better understand its behavior during the transfer. The element ability to transfer through the arc without losses have been evaluated by the "transfer ratio" which is the ratio of element content in the deposited metal to its content in the filler wire.

Two deposits were achieved with GMAW process using two filler wires with different Ti contents (Table 2) in order to determine the transfer ratio of titanium. Composition of the deposited materials was evaluated with mass spectrometry analysis and then transfer ratio of elements was deduced.

Investigated deposits showed lower Ti transfer in comparison to other elements such as chromium or molybdenum which exhibited good transfer ratio, see table 3.

\section{Table 3}


Composition of preliminary weld deposits (wt\%) measured by mass spectrometry, and transfer ratio for main elements.

\begin{tabular}{llll}
\hline Element & $\mathrm{Cr}$ & $\mathrm{Mo}$ & $\mathrm{Ti}$ \\
\hline Content in deposit 0 (\%) & 19 & 2.08 & 0.067 \\
\hline Rate transfer & 1.02 & 1.06 & 0.48 \\
\hline Content in deposit 1 (\%) & 18.8 & 2 & 0.45 \\
\hline Rate transfer & 1.02 & 1.03 & 0.61 \\
\hline
\end{tabular}

These results showed that Ti content in the metal cored filler wire had to be about twice of the amount expected in the deposit.

Seven compositions of metal cored filler wires were then elaborated (Table 4) according to these preliminary results.

\section{Table 4}

Composition of metal cored filler wires (wt $\%)$.

\begin{tabular}{|c|c|c|c|c|c|c|c|c|}
\hline Element & $\mathrm{C}$ & $\mathrm{Si}$ & $\mathrm{Mn}$ & $\mathrm{N}$ & $\mathrm{Cr}$ & Mo & $\mathrm{Ti}$ & $\mathrm{Nb}$ \\
\hline Filler wire 2 & 0.01 & 0.6 & 0.3 & 0.01 & 19 & 1.9 & $<0.1$ & 0 \\
\hline Filler wire 3 & & & & & & & 0.45 & 0 \\
\hline Filler wire 4 & & & & & & & $<0.1$ & 0.5 \\
\hline Filler wire 5 & & & & & & & $<0.1$ & 0.8 \\
\hline Filler wire 6 & & & & & & & 0.2 & 0 \\
\hline Filler wire 7 & & & & & & & 0.1 & 0.4 \\
\hline
\end{tabular}


Only $\mathrm{Ti}$ and $\mathrm{Nb}$ contents were changed in the powder mixtures used for each filler wire. The main goal of the study was to investigate the effect of these minor elements on fusion zone characteristics.

\subsection{Welding Process}

An automated GMAW process using a DIGIWAVE® generator was used for all the welding tests. The welding gas was a mixture of Ar with $2 \% \mathrm{CO}_{2}$ (AIR LIQUIDE ARCAL 12). It is usually used for welding stainless steels in automotive industry. Two set of welding parameters were determined for each filler wire which corresponded to different transfer modes: pulsed or short-circuit. Electrical parameters (voltage and current) were adjusted for each filler wire in order to get a good metal transfer and arc stability. So the electric power was slightly different for each one. Nonetheless the electric power and the welding speed were always higher in pulsed mode than those used in short-circuit mode (Table 5) for all filler metals.

\section{Table 5}

Welding parameters.

\begin{tabular}{cccc}
\hline $\begin{array}{c}\text { Transfer } \\
\text { mode }\end{array}$ & $\begin{array}{c}\text { Electric power } \\
{[\mathrm{W}]}\end{array}$ & $\begin{array}{c}\text { Welding speed } \\
{\left[\mathrm{cm} . \mathrm{s}^{-1}\right]}\end{array}$ & $\begin{array}{c}\text { Linear welding energy } \\
{\left[{\left.\mathrm{J} . \mathrm{cm}^{-1}\right]}^{-1}\right.}\end{array}$ \\
\hline Short-circuit & $1620-1840$ & 0.82 & $1945-2205$ \\
\hline Pulsed & $2540-2675$ & 1.13 & $2180-2290$ \\
\hline
\end{tabular}


The corresponding linear energy, i.e. the ratio electric power/welding speed, was a slightly higher for the pulsed mode (Table 5).

The welding tests consisted in linear weld deposits in the longitudinal direction on $2.3 \mathrm{~mm}$ thick sheets with $120 \mathrm{~mm}$ width and $400 \mathrm{~mm}$ length. Geometrical parameters concerning the position of the welding torch are given on Fig. 1.

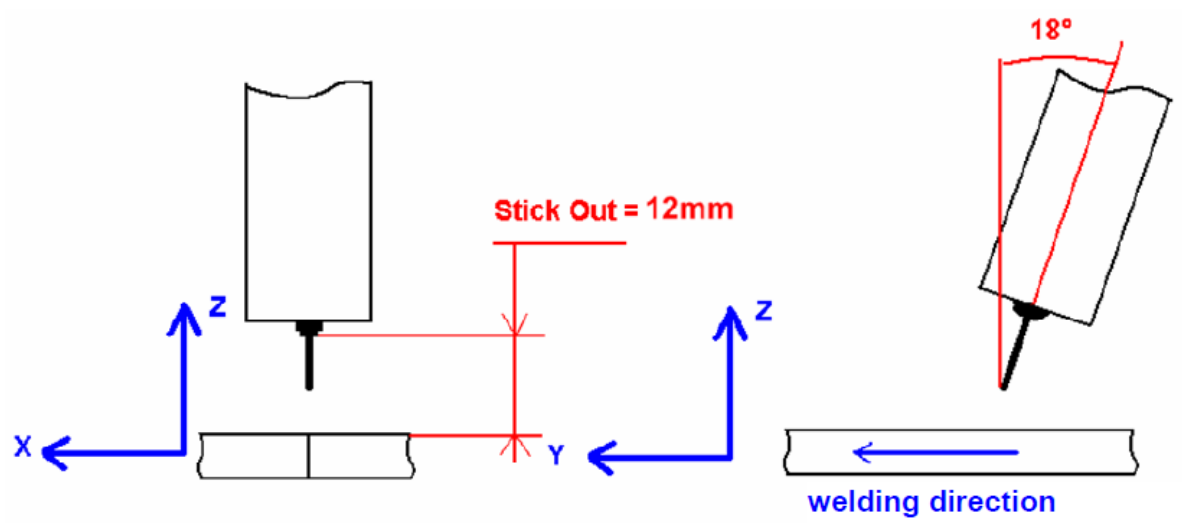

Fig. 1. Position of the welding torch.

\subsection{Characterization Methods}

Final appearance of welded samples were first visually investigated after welding in order to detect possible macroscopic defects.

Samples were cut out in the fusion zone for composition analysis using a Ametek Spectrolab mass spectrometer and an Horiba Jobin Yvon JY238 Inductive Coupled Plasma (ICP) system for minor elements like $\mathrm{C}, \mathrm{N}, \mathrm{Ti}$ and $\mathrm{Nb}$.

Finally, cross sections were cut on each welded sample then polished up to grade $4000 \mathrm{SiC}$ paper and prepared with Marble reactant $\left(4 \mathrm{~g} \mathrm{CuSO}_{4}-20 \mathrm{ml} \mathrm{HCl}-20 \mathrm{ml} \mathrm{H} 2 \mathrm{O}\right)$. Macrostructure was observed using a LEICA Z16 APO system and microstructure characteristics were analyzed using a optical microscope LEICA DMI5000M. The Interactive Measurement module of the Leica Application Suite was used to measure the dilution ratio, i.e. the 
proportion of base metal in the fusion zone and the grain size. The fusion zone was manually selected from macrographs of three cross sections for each weld. The dilution ratio was calculated by the mean ratio of base metal surface to the fusion zone surface $S_{b} /\left(S_{b}+S_{a}\right)$ measured on the three cross sections (Fig. 2). The mean grain size was calculated from a manual counting of grains in a selected area.
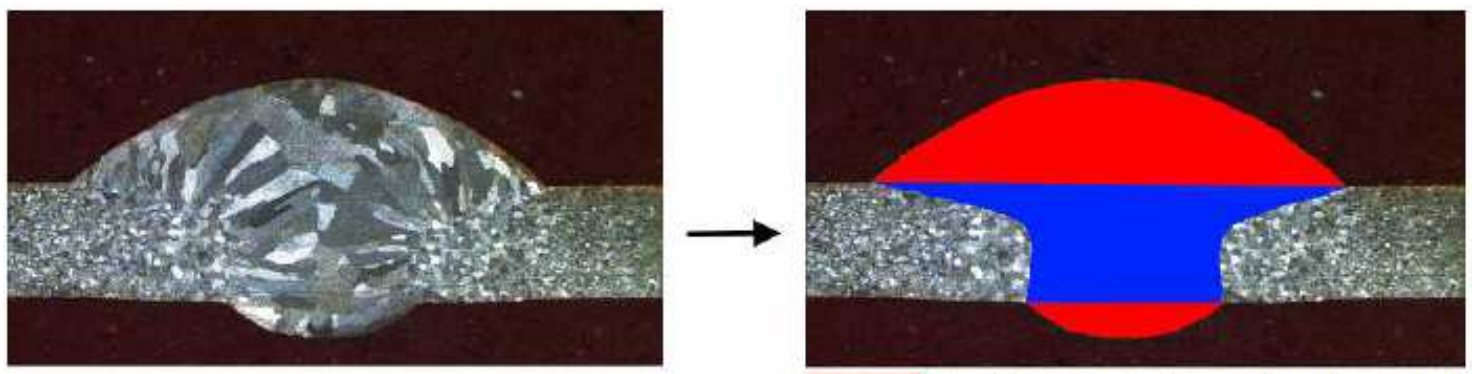

Surface of deposited metal $\mathrm{S}_{\mathrm{a}}$

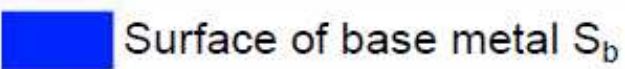

Fig. 2. Measures of the surfaces for the calculation of the dilution ratio.

Some samples were also investigated using a scanning electron microscope JEOL 7000F equipped with an Energy-Dispersive X-ray Spectroscopy (EDS) facility.

\section{Results and Discussion}

\subsection{Composition of Fusion Zones}

All filler wires had the same $\mathrm{Cr}$ and Mo weight percents as base metal (19\% and 1.9\% respectively). Transfer ratio of these elements was almost equal to 1 (as stated in §2.2, table 3) so their contents in the fusion zones were expected to be similar to the base metal one. The weight percents measured by mass spectrometry were about 18.5 to $19 \%$ for $\mathrm{Cr}$ and 1.9 to $2.1 \%$ for Mo in the fusion zones of some samples what confirmed this assumption. 
Conversely $\mathrm{Ti}$ and $\mathrm{Nb}$ percentages were rather different in the filler wires and in the base metal. Titanium is especially sensitive to oxidation so its content in the deposited metal was always lower than the one in the filler wire. Consequently it was difficult to control its percentage in the fusion zone.

Compositions of fusion zones obtained with all the seventh filler wires are shown in table 6 .

These compositions were measured with ICP for both pulsed and short circuit modes.

\section{Table 6}

Composition of the fusion zones obtained with different filler wires measured by ICP.

\begin{tabular}{llllllllll}
\hline & \multicolumn{1}{l}{ Pulsed mode } & \multicolumn{5}{c}{ Short-circuit mode } \\
\hline Element & $\mathrm{C}$ & $\mathrm{N}$ & $\mathrm{Ti}$ & $\mathrm{Nb}$ & $\mathrm{C}$ & $\mathrm{N}$ & $\mathrm{Ti}$ & $\mathrm{Nb}$ \\
\hline Filler wire 2 & - & - & 0.045 & 0.21 & - & - & 0.055 & 0.15 \\
\hline Filler wire 3 & 0.030 & 0.0190 & 0.26 & 0.23 & 0.041 & 0.0194 & 0.37 & 0.21 \\
\hline Filler wire 4 & 0.037 & 0.0205 & 0.067 & 0.68 & 0.038 & 0.0221 & 0.065 & 0.58 \\
\hline Filler wire 5 & 0.032 & 0.0202 & 0.050 & 0.71 & - & - & 0.055 & 0.71 \\
\hline Filler wire 6 & 0.036 & 0.0210 & 0.097 & 0.33 & 0.035 & 0.0205 & 0.11 & 0.30 \\
\hline Filler wire 7 & 0.036 & 0.0202 & 0.051 & 0.53 & 0.037 & 0.0192 & 0.063 & 0.53 \\
\hline Filler wire 8 & 0.037 & 0.0231 & 0.15 & 0.44 & 0.037 & 0.0223 & 0.16 & 0.42 \\
\hline
\end{tabular}

The analysis technique was only calibrated for $\mathrm{Ti}, \mathrm{Nb}, \mathrm{N}$ and $\mathrm{C}$ elements so the contents measured for other elements were not indicated because of the lower accuracy of the measures. All the fusion zones resulted with high $\mathrm{C}$ percentage, about twice the content in the base metal or in the filler wires. Kotecki (2001) explained this carbon enrichment was due to molten metal interaction with welding gas which contained $2 \% \mathrm{CO}_{2}$. Nitrogen percentage was 
also slightly higher in the fusion zone due to the pollution of protective gas by atmospheric nitrogen. Oxygen content was not measured in the fusion zones but its percentage was also expected to be high due to the interaction with $\mathrm{CO}_{2}$. There were no significant differences between various samples what indicated no sensitive effect of filler metal composition and welding mode on $\mathrm{C}$ and $\mathrm{N}$ contents.

Titanium and niobium weight percent were rather different in the obtained fusion zones with various filler wires and welding modes. Their contents in the deposited metals were deduced from the ICP analysis of the fusion zone, according to the dilution ratio calculated from the macrographs of samples transverse cut (Fig. 2), and the base metal composition. Transfer ratio for titanium and niobium calculated from these values are compared in fig. 3.

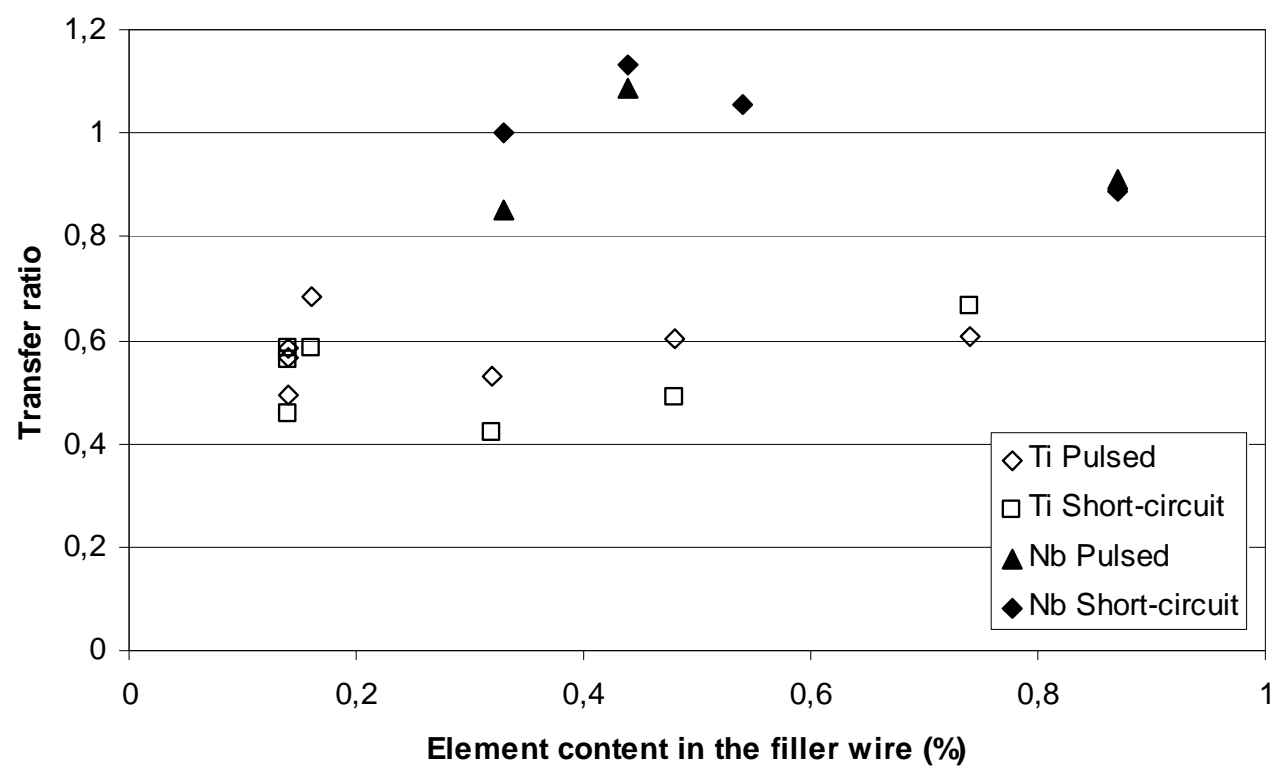

Fig. 3. Transfer ratio of titanium and niobium during arc welding versus element content.

Neither the content of the element in the filler wire nor on the transfer mode seemed to affect these transfer ratios. Niobium ratio was high close to one whereas titanium ratio was lower, between 0.4 and 0.7 as expected. 
Titanium has a great affinity with oxygen which comes from the $\mathrm{CO}_{2}$ decomposition in the arc as well as with nitrogen present as impurities in the welding gas due to atmosphere pollution. Some part of titanium in the filler wire has likely reacted to form oxides, nitrides, or other compounds, and remained outside of the molten zone. The observation of weld surfaces with filler wires that contained high titanium contents showed less oxidization than those welded with filler wire without titanium (Fig. 4).
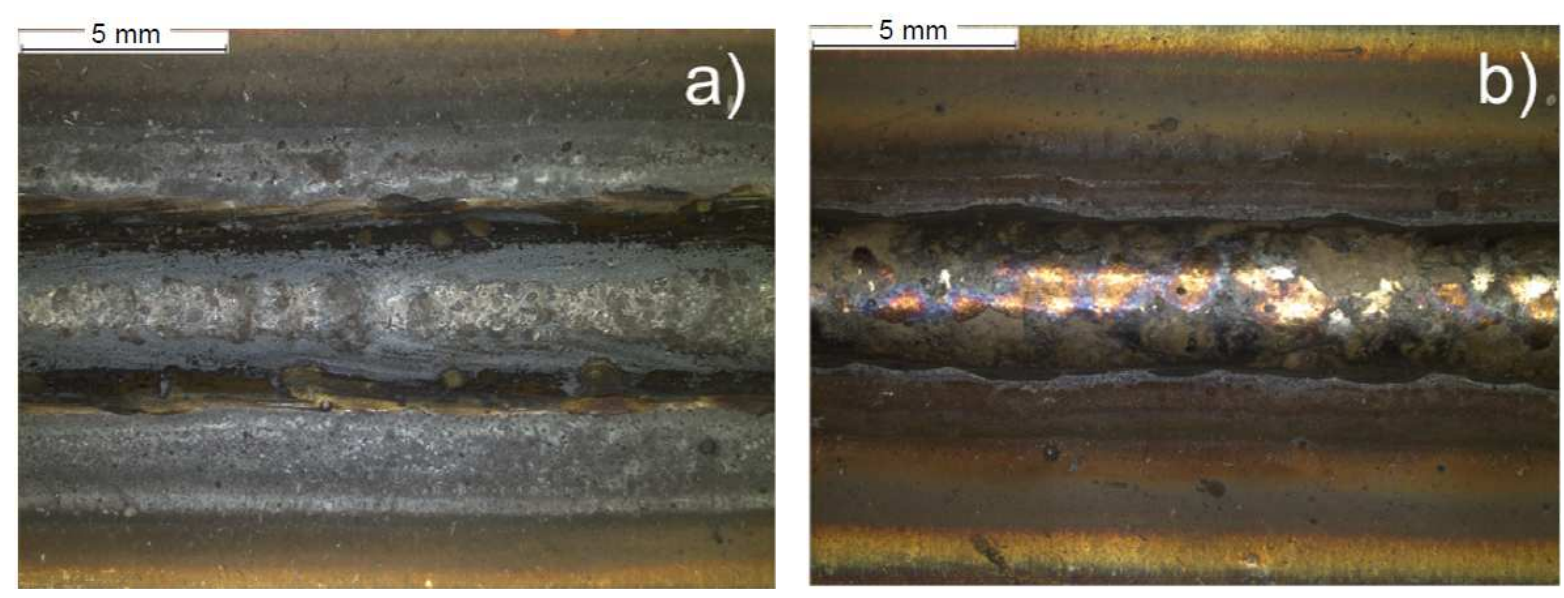

Fig. 4. Comparison of the surface aspect of welds obtained with (a) filler wire No. $4(<0.1 \%$ Ti) and (b) filler wire No. $3(0.45 \% \mathrm{Ti})$.

It is assumed that titanium in the filler wire "consumed" the residual oxygen in the gas during the metal transfer and then it protected the weld from the oxidation during welding.

\subsection{General Aspect of the Welds}

The addition of titanium in the filler wire seemed to have a detrimental effect on the arc stability for both transfer modes because it was observed that the welding lines were less regular with the increase of Ti content. Jonsson et al. (1995) demonstrated that GMAW arc stability was promoted by a slight oxidation of the surface of parent metal improving electron 
emission from the cathode. So the possible oxygen consumption with titanium limited the surface oxidation of the base metal and then the electronic emission required for arc stability. Cleanest surface aspect of welded samples made with filler wires containing more amount of titanium confirmed this assumption as observed on Fig. 4. These welded samples exhibited losses of $\mathrm{Ti}$ in the fusion zone in comparison to its content in the filler wire.

Welds obtained in pulsed transfer modes (Fig.5) always presented a more flat shape and were more regular than in short-circuit mode as generally observed in GMAW welds.
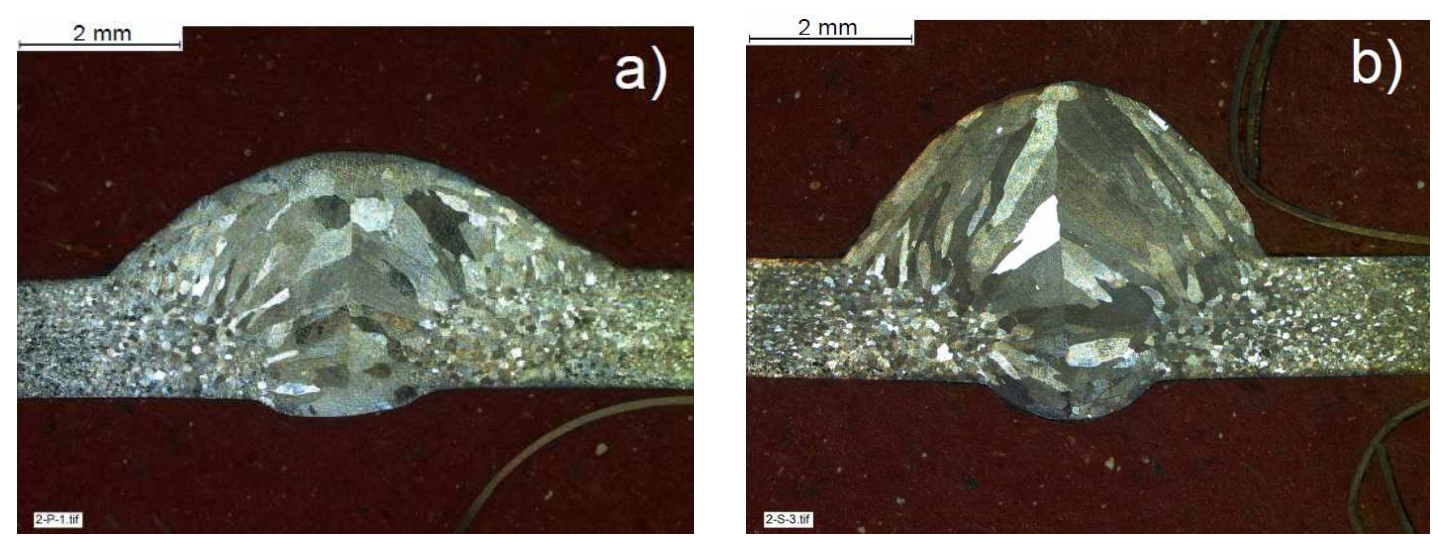

Fig. 5. Cross sections of welds obtained with filler wire 2, (a) in pulsed transfer mode, (b) in short-circuit transfer mode.

This is mainly due to the temperature of the deposited metal which was higher in pulsed mode. The "pulse" produced a rapid melting of the filler wire which created a drop that fell straight down into the weld pool. Conversely, electric power used for short-circuit mode was not high enough to separate the liquid drop from the wire. Thus the temperature of the deposited metal remained slightly higher than the liquidus temperature. The mechanical arc pressure effect promotes the wetting of molten metal. This effect was also more important in 
pulsed mode because the arc was always formed contrary to short-circuit mode. Arc pressure was also higher during the pulse as current increased.

The dilution ratio, i.e. the proportion of base metal in the fusion zone, was lower in shortcircuit mode for all the filler wires (about $30 \%$ versus $43 \%$ in pulsed mode). That could be also a result of the higher temperature of the deposited metal in pulsed mode which allowed the melting of a bigger volume of base metal for the same volume of deposited metal.

The general shape of the fusion zone also changed with the titanium content (Fig. 6).
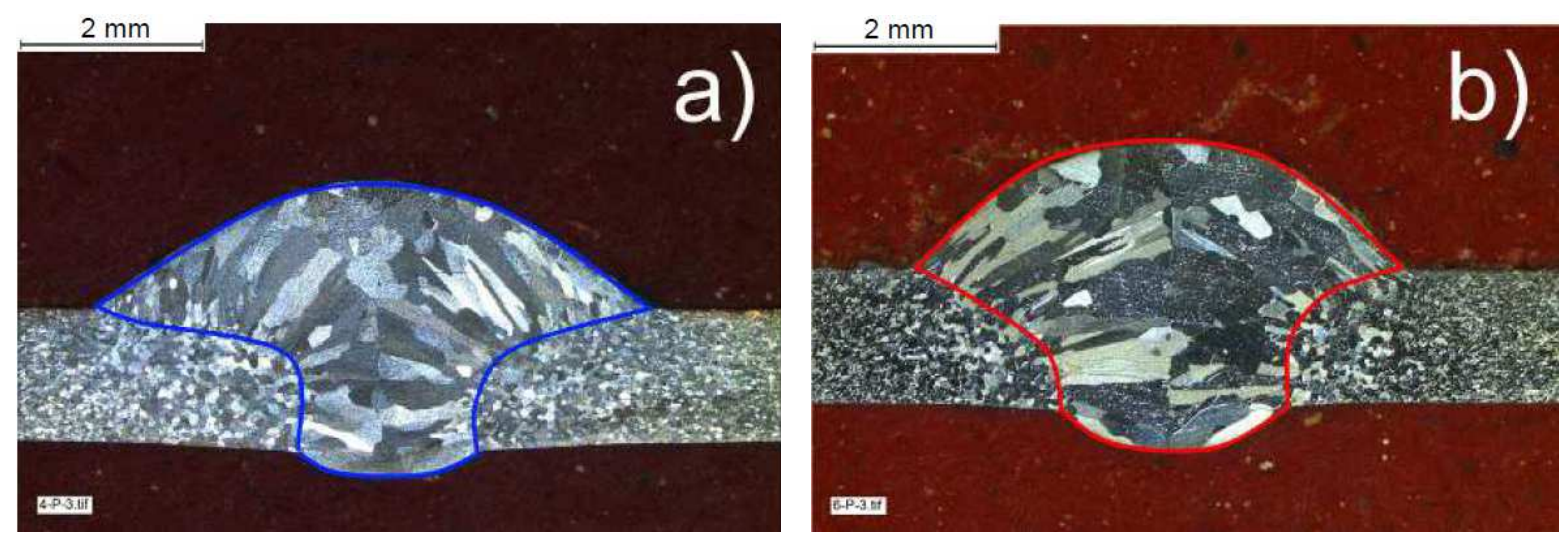

Fig. 6. Shape of the fusion zone, (a) without titanium, (b) with titanium.

As a matter of fact, the wetting angle was increased with Ti content (Fig. 7). 


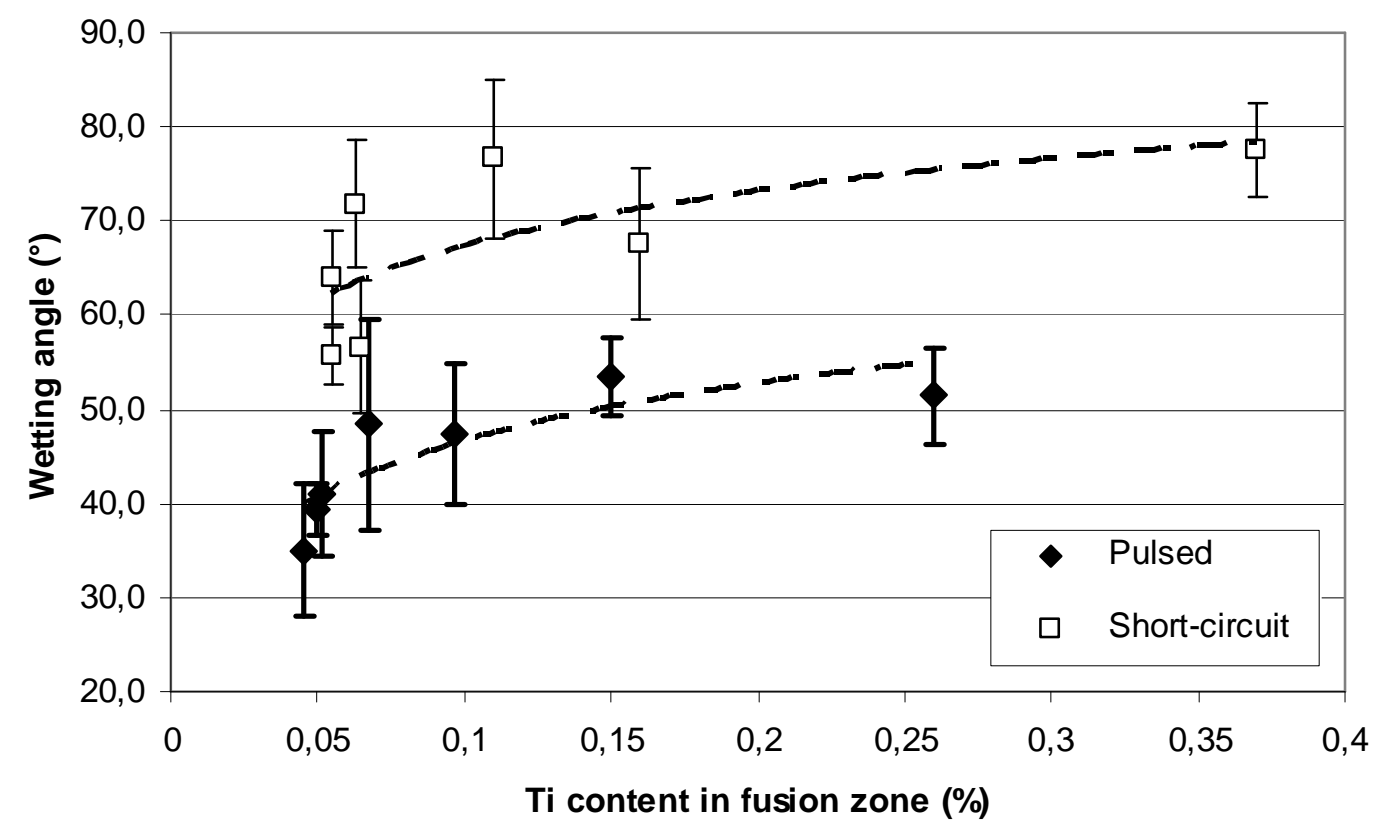

Fig. 7. Wetting angle versus titanium content in the fusion zone.

Furthermore, the penetration depth of the weld seemed to be affected with Titanium content. Without titanium, the fusion zones were wider on the upper side and narrower on the back side whereas the width of upper and back sides were closer in the fusion zones containing $\mathrm{Ti}$ (Fig. 6).

Xu et al. (2007) stated that fusion zone profiles in welds can be explained with Marangoni convection in the weld pool surface which is controlled through the surface tension temperature coefficient. Surface tension coefficient is quite sensitive to active elements like sulphur or oxygen. Presence of such elements led to inward Marangoni convection what results in deeper weld pool shape. Presence of titanium has likely changed oxygen concentrations due to its great affinity with this element and thus the surface tension coefficient promoting inward Marangoni convection in the weld pool. That could also explain the increase of the wetting angle with Ti content in the fusion zone. 


\subsection{Microstructure of Welded Zones}

Different grain size and morphology were observed in the obtained fusion zones with various filler wires used (Figs. 8-9).
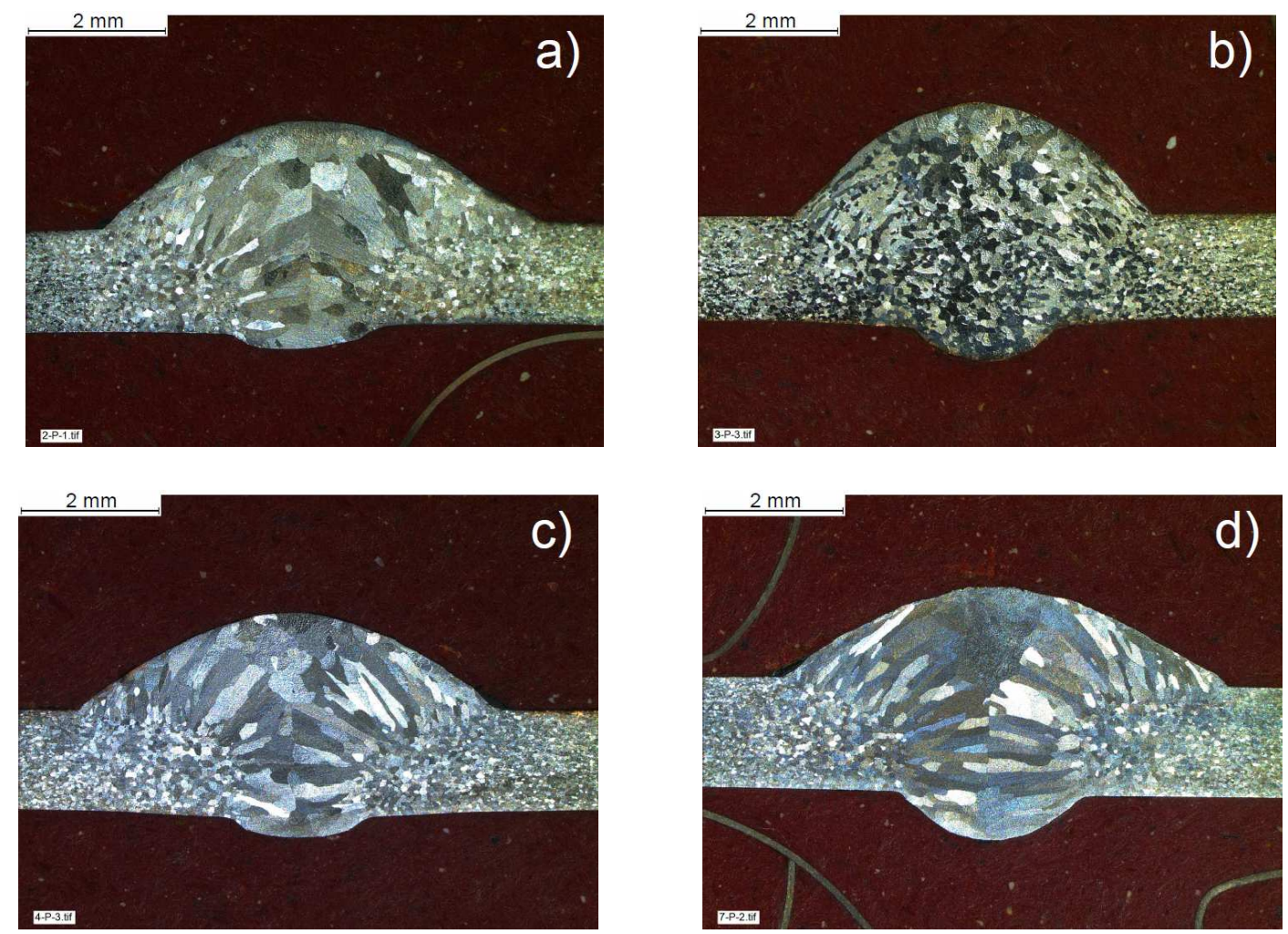

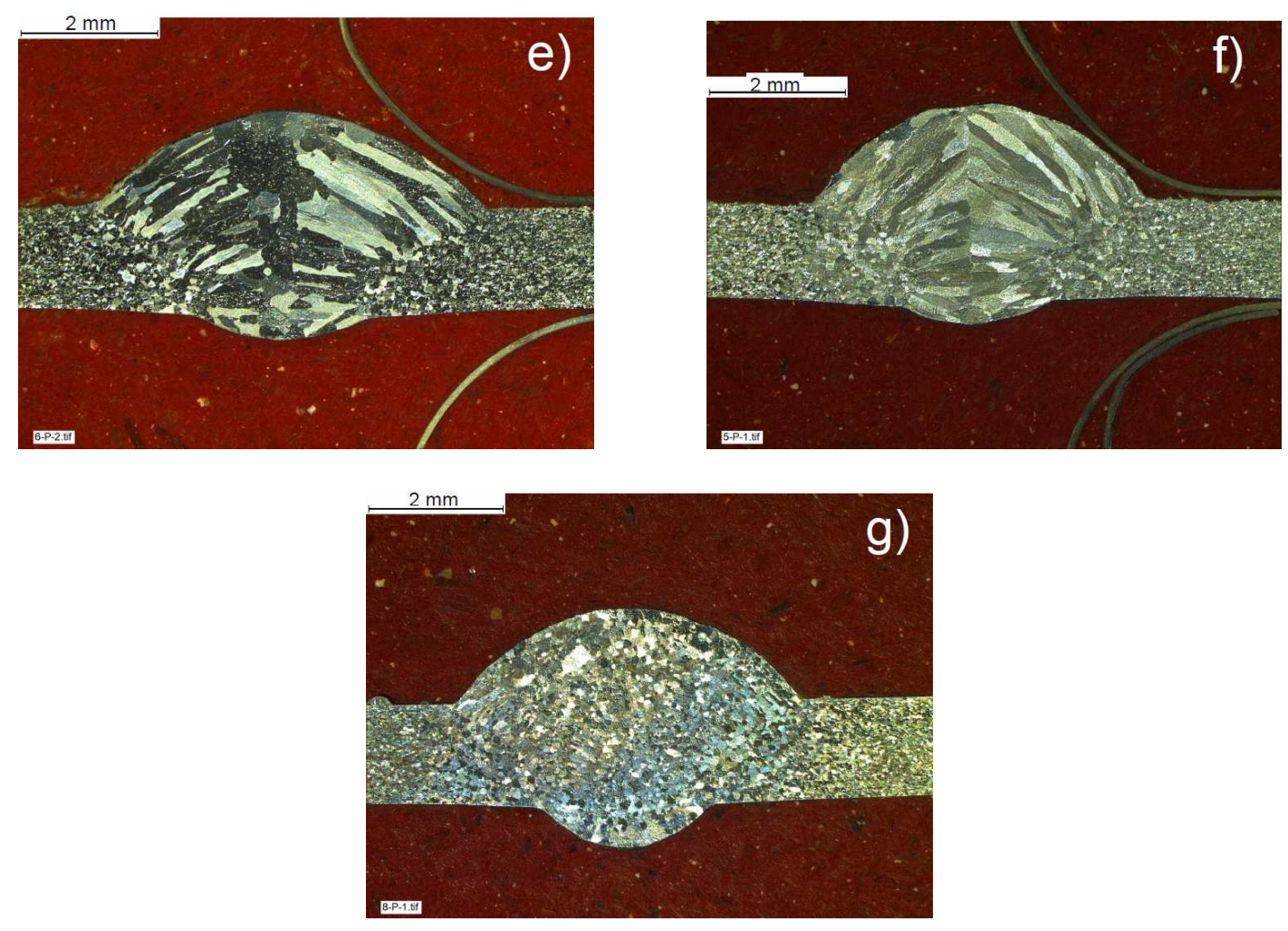

Fig. 8. Grain structure of fusion zones obtained with various filler wires in pulsed mode: (a)

filler wire 2, (b) filler wire 3, (c) filler wire 4, (d) filler wire 5, (e) filler wire 6, (f) filler wire 7 and (g) filler wire 8.
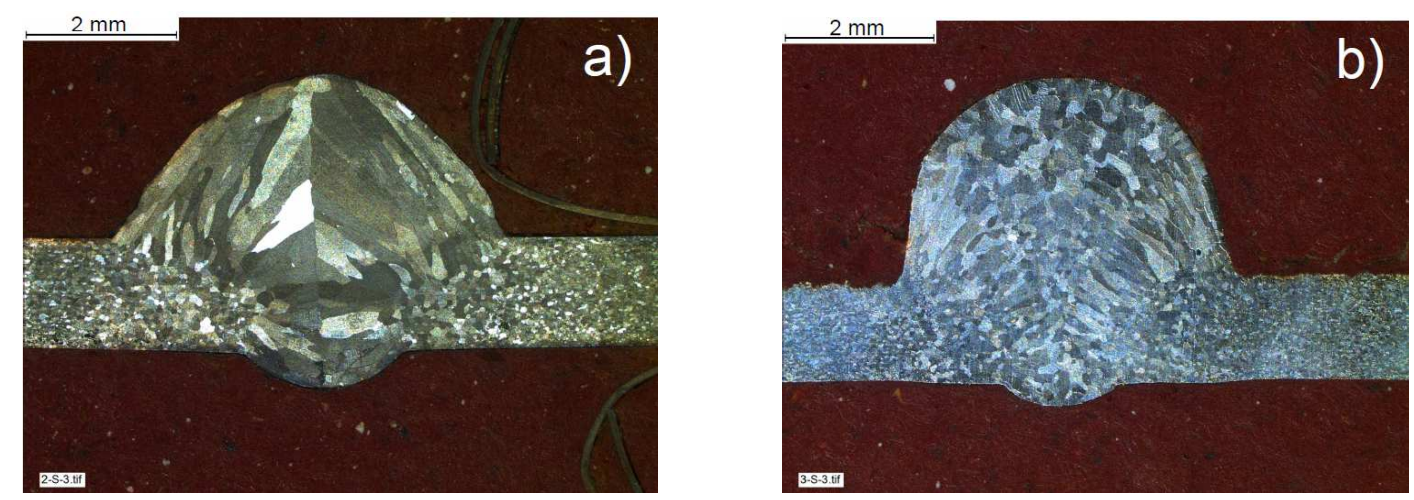

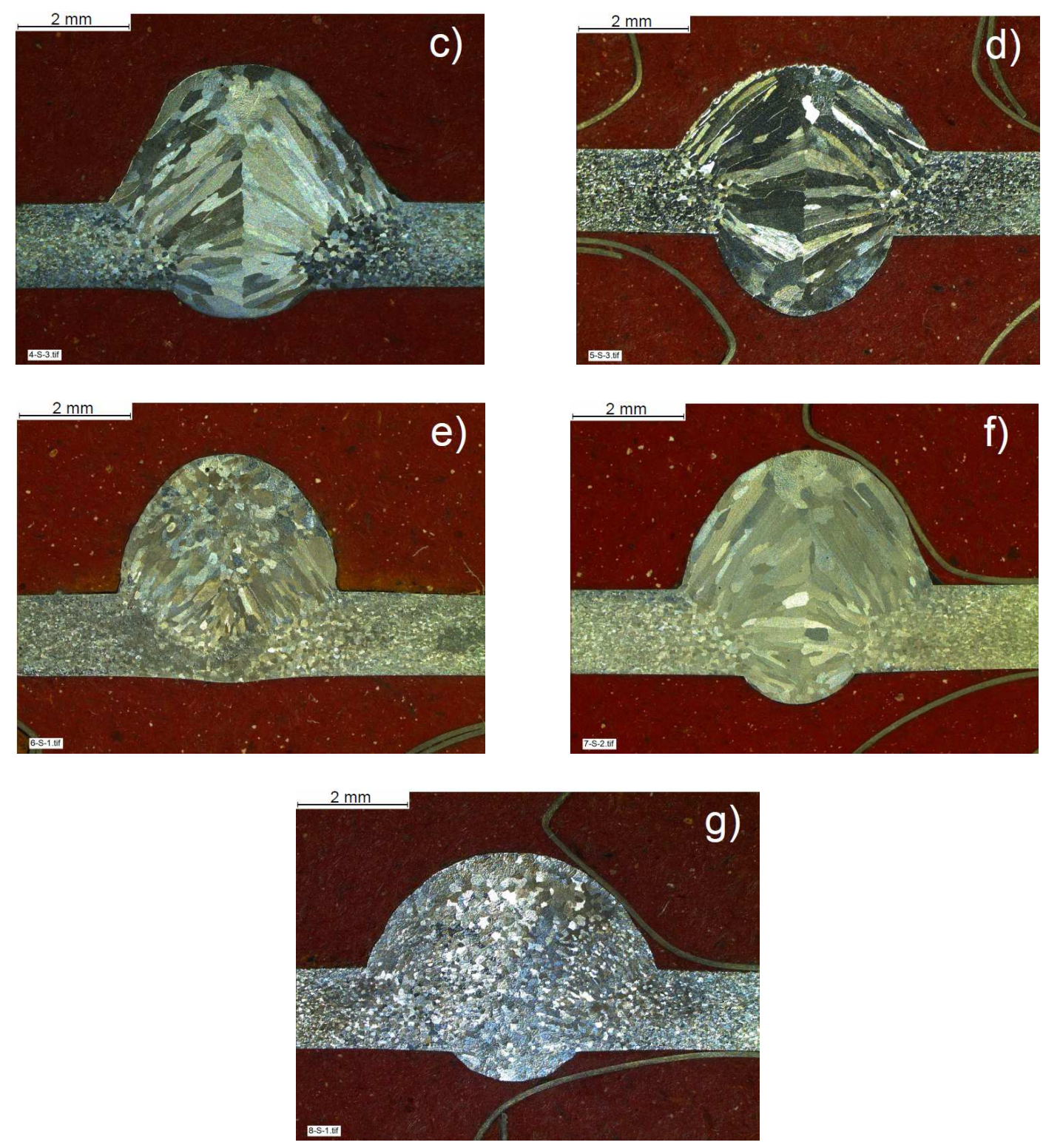

Fig. 9. Grain structure of fusion zones obtained with various filler wires in short-circuit mode:

(a) filler wire 2, (b) filler wire 3, (c) filler wire 4, (d) filler wire 5, (e) filler wire 6, (f) filler wire 7 and $(\mathrm{g})$ filler wire 8.

Most of samples showed large columnar grains were formed with 200-500 $\mu \mathrm{m}$ width and more than $1 \mathrm{~mm}$ long (Fig. 10a). They were oriented in the direction of the heat flux. 

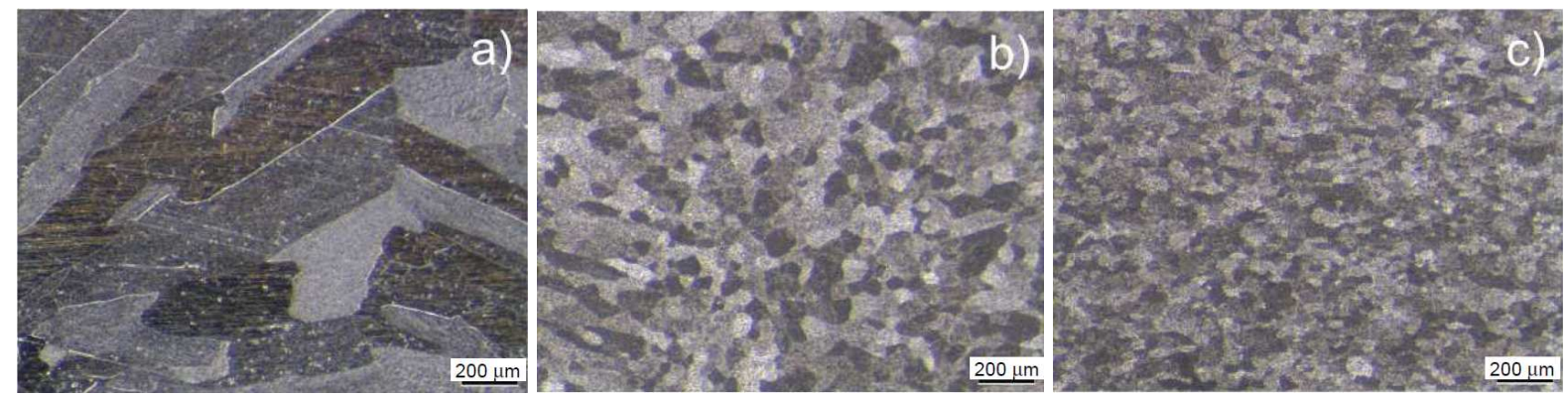

Fig. 10. Microstructural morphologies of grains: (a) columnar grains in the fusion zone, (b) equiaxed grains in the fusion zone, and (c) base metal.

These grains grew by epitaxy during solidification from the grains of the base metal in the border of the fusion line. In some cases, smaller grains with an equiaxed shape were observed on the centre of the fusion zone, and exceptionally in all the fusion zone. The mean grain size was generally a little bit higher than the base metal (Figs. 10b-c).

The columnar to equiaxed grains transition (CET) can occur during a solidification process when the liquid located just in front of the solidification front is undercooled. The main mechanism responsible of this phenomenon is the constitutional undercooling which results from the release of solute elements in the liquid surrounding the solidification front. The increase of solute content in the alloy generally decreases the liquidus temperature that stops or slows down the advance of the solidification front. In the liquid behind this solute rich layer, the liquidus temperature remains high due to the lower content of solute elements and can become higher than the local temperature of the liquid. Nuclei can then be formed in this zone what lead to the formation of new equiaxed grains. Dantzig and Rappaz ( 2009) explained that CET could appear if the growth rate of these new equiaxed grains was higher than the growth rate of columnar grains.

Lippold and Kotecki (2005) stated that better mechanical properties are obtained with a fine and equiaxed grain structures. So equiaxed structure as fine as possible should be promoted 
during welding process. The proportion of equiaxed grains was discussed regarding to the compositions of the fusion zones. Only $\mathrm{Nb}$ and $\mathrm{Ti}$ contents changed in the different obtained fusion zones in this study. The obtained fusion zones with filler wires 2, 4, 5 and 7 which contained about the same Ti content $(0.05 \%)$ but various $\mathrm{Nb}$ contents from 0.15 to $0.7 \%$ exhibited rather similar grain morphologies, with a columnar structure in most of the fusion zone. Grain morphology has not been affected with niobium content. Conversely, an increase of Ti content seemed to increase the fraction of equiaxed grains in the fusion zone. Evolution of equiaxed grains fraction in the fusion zone versus Ti content is presented in fig. 11.

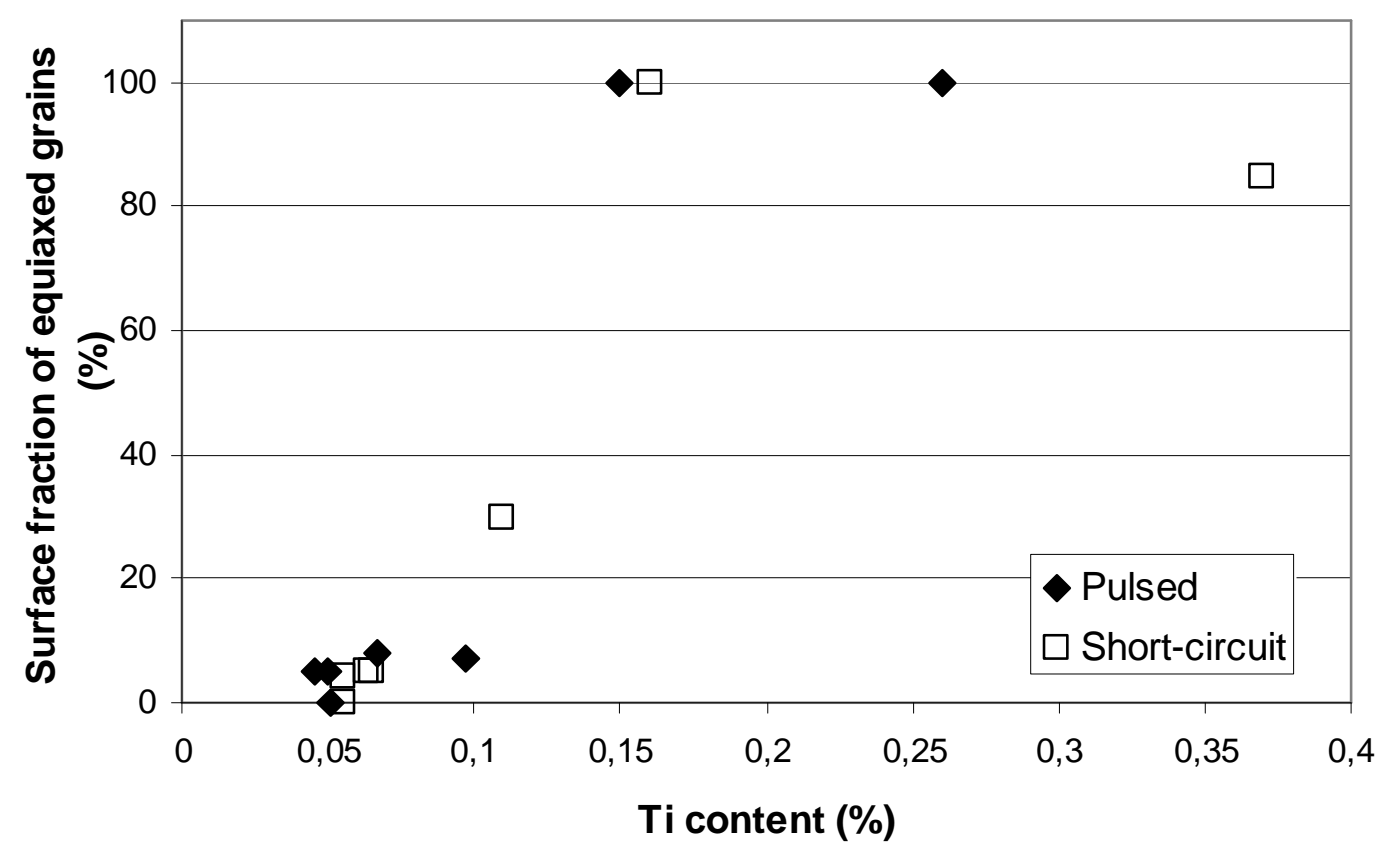

Fig. 11. Fraction of equiaxed grains in the fusion zone versus titanium content.

Low Ti contents led to fusion zone with a columnar structure whereas high Ti contents generated an equiaxed structure. In the fusion zones containing about 0.1 to $0.15 \% \mathrm{Ti}$, the CET was clearly observed in the fusion zone (Fig. 9e), with columnar grains in the peripheral 
zone and equiaxed grains in the centre. For higher Ti contents, the CET appeared just at the beginning of the weld pool solidification, so columnar grains had no time to grow.

This transition between mainly columnar grains to mainly equiaxed grains fusion zone occurred for the same Ti content in pulsed mode and in short circuit mode. Apparently, the transfer mode had no significant influence on the surface fraction of equiaxed grains.

The inoculant effect of Ti has been extensively studied by Greer et al. (2003) for aluminium alloys. In these alloys, Ti formed refractory compounds on the molten metal that acted as heterogeneous nucleation sites for the grains solidification. Ostrowski and Langer (1979) demonstrated that $\mathrm{Ti}$ was also a grain refiner for steels or stainless steels but the nucleation mechanism is not yet elucidated. Villafuerte et al. (1995) and more recently Amuda and Mridha (2012) observed that the effect of titanium was not the same as it was introduced as oxide or metal. Mechanisms seemed also to be different when Ti was introduced alone or combined with other metals during welding of FSS.

The observation of the microstructure of the fusion zone at higher magnification with scanning electron microscope showed very fine particles uniformly dispersed. EDS analysis indicated two kind of particles, niobium rich in light contrast, and titanium rich particles in dark contrast. These last ones were finer and more numerous than Nb-rich particles (Fig. 12).

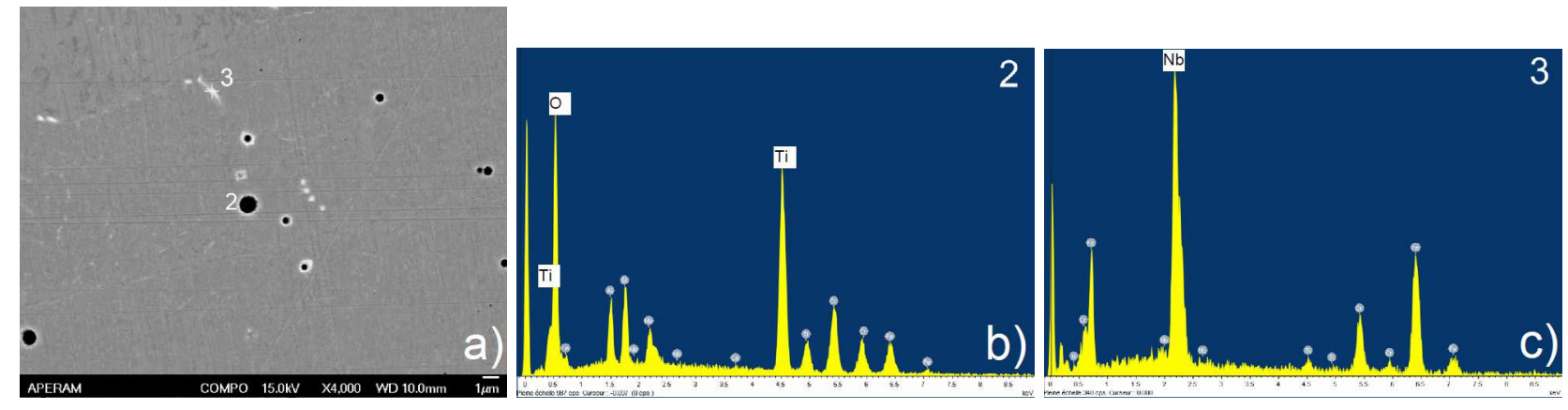

Fig. 12. (a) SEM micrograph, and EDS analyses of (b) dark precipitates and (c) light precipitates formed in the fusion zones. 
A measurement of the particle densities using image analysis indicated differences between samples. As expected, samples more rich in Ti contained more titanium precipitates what could explain the nucleation of equiaxed grains.

Results presented in this section indicated a minimum content of titanium in the fusion zone of about $0.15 \%$ is required to form a fusion zone with completely equiaxed grain (this corresponded to a content of $0.3 \%$ in the filler wire). A higher content of titanium may have a detrimental effect on the mechanical properties, especially for the toughness and ductility. Thus, filler wire number 8 seemed the best suited for welding the K44X steel.

\section{Conclusions}

The development of seven metal cored filler wires for GMAW welding a 444 ferritic stainless steel with $19 \% \mathrm{Cr}, 1.9 \%$ Mo and various $\mathrm{Nb}$ and Ti contents, was conducted successfully. Niobium was added to improve the high temperature mechanical properties but it had no significant effect on the shape and on the grain structure of the fusion zone.

Conversely, titanium increased the wetting angle, improved the penetration of the weld pool, and promoted the columnar to equiaxed grain transition (CET) in the fusion zone.

A minimum Ti content of about $0.15 \%$ in the fusion zone was required to form a completely equiaxed structure. Due to the low transfer ratio of titanium during the welding, the content in the filler wire had to be twice time the expected content in the fusion zone, i.e. $0.3 \%$. Among the seven developed filler wires, the filler wire $\mathrm{N}^{\circ} 8$ with $0.3 \% \mathrm{Ti}$ and $0.3 \% \mathrm{Nb}$ was the best suited candidate for the application.

\section{Acknowledgements}


The authors wish to thank Joel Claeys and Bertrand Petit, from Aperam, Isbergues, for supplying the K44X steel.

\section{References}

Amuda, M.O.H., Mridha, S., 2011. An Overview of Sensitization Dynamics in Ferritic

Stainless Steel Welds. International Journal of Corrosion 2011, Article ID 305793, 9 pages. DOI:10.1155/2011/305793.

Amuda, M.O.H., Mridha, S., 2012. Comparative evaluation of grain refinement in AISI 430 FSS welds by elemental metal powder addition and cryogenic cooling. Materials \& Design 35, 609-618.

Bayraktar, E., Moiron, J., Kaplan, D., 2006. Effect of welding conditions on the formability characteristics of thin sheet steels: Mechanical and metallurgical effects. Journal of Materials Processing Technology 175, 20-26.

Dantzig, J.A., Rappaz, M., 2009. Solidification, first ed. EPFL Press, Lausane, pp. 452-456.

Demo, J., 1974. Weldable and corrosion-related ferritic stainless-steels. Metallurgical Transactions 5, 2253-2256.

Faivre, L., Santacreu, P.O., Leseux, J., 2011. Thermal fatigue resistance of MIG/MAG and laser welded joints in stainless steel exhaust manifolds. In: Tecnol. Metal. Mater. Miner., São Paulo, 8, pp. 24-30. DOI: 10.4322/tmm.2011.005. 
Flemings, M.C., 1974. Solidification processing. Metallurgical Transactions, 5, 2121-2134.

Fujita, N., Ohmura K., Yamamoto, A., 2003. Changes of microstructures and high temperature properties during high temperature service of niobium added ferritic stainless steels. Materials Science and Engineering A351, 272-281.

Gordon, W., Van Bennekom, A., 1996. Review of stabilisation of ferritic stainless steels. Materials Science and Technology 12, 126-131.

Greeff, M. L., Du Toit, M., 2006. Looking at the sensitization of 11-12\% chromium EN 1.4003 stainless steels during welding. Welding Journal 85, 243s-251s.

Greer, A. L., Cooper, P. S., Meredith, M. W., Schneider, W., Schumacher, P., Spittle, J.A., Tronche, A., 2003. Grain refinement of aluminium alloys by inoculation. Advanced Engineering Materials 5, 81-91.

Jönsson, P.G., Murphy, A.B., Szekely J., 1995. The influence of oxygen additions on argonshielded gas metal arc welding processes. Welding Journal 74, 48s-58s.

Kotecki, D., 2001. Carbon pickup from argon- $\mathrm{CO}_{2}$ blends in GMAW. Welding Journal 80, $43-48$.

Lakshminarayanan, A.K., Shanmugam, K., Balasubramanian, V., 2009. Effect of autogenous arc 
welding processes on tensile and impact properties of ferritic stainless steel joints. Journal of Iron and Steel Research, International, 16, 62-68.

Lippold, J.C., Kotecki, D.J., 2005. Welding metallurgy and weldability of stainless steels. Wiley Interscience Publication, Hoboken, New Jersey, pp. 101-104.

Mallaiah, G., Kumar, A., Ravinderreddy, P., Madhusudhanreddy, G., 2012. Influence of grain refining elements on mechanical properties of AISI 430 ferritic stainless steel weldments taguchi approach. Materials \& Design 36, 443-450.

Miyasaki, A., Hirasawa, J., Furukimi, O., 2003. Development of high heat-resistant ferritic stainless steel with high formability, "RMH-1", for automotive exhaust manifolds by optimizing Mo composition design. Kawasaki Steel Technical Report 48, 28-32.

Ostrowski, A., Langer, E.W., 1979. Precipitation of titanium carbonitrides in as cast 17\% chromium stainless steels. Scandinavian Journal of Metallurgy 8, 153-160.

Pickering, F. B., 1978. Physical Metallurgy and the Design of Steels. Applied Science Publishers LTD, London.

Potgieter, J.H., Sephton, M., Nkosi, Z.W., 2007. Corrosion of hot end automotive exhaust components. Anti-Corrosion Methods and Materials 54, 180-187.

Santacreu, P.O., Cleizergues, O., Simon, C., Duroux, P., 2004. Design of stainless steel automotive exhaust manifolds. La Revue de Métallurgie 101, 615-620. 
Santacreu, P.O., Bucher, L., Koster, A., Remy, L., 2006. Thermomechanical fatigue of stainless steels for automotive exhaust systems. La Revue de Métallurgie 103, 37-42.

Santacreu, P.O., Saedlou, S., Faivre, L., Acher, A., Leseux, J., 2011. Ferritic Stainless Steel Grade with Improved Durability for High Temperature Exhaust Manifold. SAE Technical Paper 2011-01-0194. DOI:10.4271/2011-01-0194.

Silva, C.C., Farias, J.P., 2008. Microstructural characterization of the haz in aisi 444 ferritic stainless steel welds. Materials Characterization 59, 528-533.

Taban, E. Deleu, E., Dhooge, A., Kaluc, E., 2009. Laser welding of modified 12\% Cr stainless steel: strength, fatigue, toughness, microstructure and corrosion properties. Materials \& Design, 30, 1193-1200.

Villafuerte J.C., Kerr, H.W., David, S.A., 1995. Mechanisms of equiaxed grain formation in ferritic stainless steel gas tungsten arc welds. Materials Science and Engineering A194, 187191.

Xinzhong, L., Jingtuo, H., Wanhua, Y., Shifeng, D., 2008. Structure change of 430 stainless steel in the heating process. Journal of University of Science and Technology Beijing, Mineral, Metallurgy, Material 15, 34-37.

Xu, Y., Dong, Z., Wei, Y., Yang, C., 2007. Marangoni convection and weld shape 
variation in A-TIG welding process. Theoretical and Applied Fracture Mechanics 48, 178186.

You, X.M., Jiang, Z.H., Li, H.B., 2007. Ultra-pure ferritic stainless steels grade, refining operation and application. Journal of Iron and Steel Research, International 14, 24-30. 


\section{Table Captions}

\section{Table 1}

Composition of K44X grade.

\section{Table 2}

Composition of the foil and global compositions of metal cored filler wires used for preliminary welding (wt \%).

\section{Table 3}

Composition of preliminary weld deposits (wt\%) measured by mass spectrometry, and transfer ratio for main elements.

\section{Table 4}

Composition of metal cored filler wires (wt\%).

\section{Table 5}

Welding parameters.

\section{Table 6}

Composition of the fusion zones obtained with the different filler wires measured by ICP. 


\section{Figures Captions}

Fig. 1. Position of the welding torch.

Fig. 2. Measures of the surfaces for the calculation of the dilution ratio.

Fig. 3. Transfer ratio of titanium and niobium during arc welding versus element content.

Fig. 4. Comparison of the surface aspect of welds obtained with (a) filler wire No. $4(<0.1 \%$ Ti) and (b) filler wire No. $3(0.45 \% \mathrm{Ti})$.

Fig. 5. Cross sections of welds obtained with filler wire 2, (a) in pulsed transfer mode, (b) in short-circuit transfer mode.

Fig. 6. Shape of the fusion zone, (a) without titanium, (b) with titanium.

Fig. 7. Wetting angle versus titanium content in the fusion zone.

Fig. 8. Grain structure of fusion zones obtained with various filler wires in pulsed mode: (a) filler wire 2, (b) filler wire 3, (c) filler wire 4, (d) filler wire 5, (e) filler wire 6, (f) filler wire 7 and $(\mathrm{g})$ filler wire 8 .

Fig. 9. Grain structure of fusion zones obtained with various filler wires in short-circuit mode: (a) filler wire 2, (b) filler wire 3, (c) filler wire 4, (d) filler wire 5, (e) filler wire 6, (f) filler wire 7 and $(\mathrm{g})$ filler wire 8. 
Fig. 10. Microstructural morphologies of grains: (a) columnar grains in the fusion zone, (b) equiaxed grains in the fusion zone, and (c) base metal.

Fig. 11. Fraction of equiaxed grains in the fusion zone versus titanium content.

Fig. 12. (a) SEM micrograph, and EDS analyses of (b) dark precipitates and (c) light precipitates formed in the fusion zones. 